\title{
ANALISA WAKTU TUNGGU DI LAYANAN ADMINISTRASI AKADEMIK UNIVERSITAS BUNDA MULIA DENGAN METODE SIMULASI
}

\author{
Ir. Rudy Santosa Sudirga, MM \\ Email: rudysudirga@yahoo.com
}

\section{Penulis}

Ir. Rudy Santosa Sudirga, MM adalah staf pengajar tetap di Jurusan Manajemen, Universitas Bunda Mulia, Jakarta, dalam bidang manajemen operasi, manajemen sains dan manajemen pemasaran.

\section{Abstrak}

Academic Administration Service management continues to be a major challenge for many Universities or school organizations as Universities are required to provide more services with less resources. Short response times for service are essential to avoid disruptions to University's day to day activities or Academic Administration Service's facilities. Managers must regularly assess their manpower needs, and ensure that their allocations and operational decisions lead to the best service at the lowest cost. Service staff allocation and response-time in service involves many challenging problems, because the mean and variance of the response-time in service can increase dramatically with traffic intensity, consequently the design for this system has to be able to cope with this complication. This experiment discusses how to use simulation model to improve response-time in service operations. Simulation experiments for analyzing the steadystate behavior of queuing systems over a range of traffic intensities are considered the best method of solution. 
The technique of simulation consists of taking random samples from the probability distribution which represents the real-world system.

In this research the effects of dependent departure intervals on waiting times are examined for a one-station queuing system, and inter-arrival times are compared to a computer-simulated inter-arrival times having dependent arrivals. Significant differences in service times are found due to the mean and variance of the service times.

The purpose of this research is to propose a new dynamic-server queuing model to increase system efficiency and customer satisfaction compared with the current practice.

\section{Kata Kunci}

Interarrival Time, Service Time, and Simulation.

\section{PENDAHULUAN}

Dengan bertambahnya mahasiswa dan dosen di Universitas Bunda Mulia, maka bertambah sibuklah pelayanan bagian LAA (Layanan Administrasi Akademik) di Universitas Bunda Mulia di lantai enam. Manajer di bagian LAA akan sangat disibukkan dengan alokasi penempatan staf untuk menjamin agar LAA dapat memberikan pelayanan yang terbaik kepada para mahasiswa dan dosen dan memberikan keputusan yang terbaik pula dari sisi operasional.

Oleh karena itu penulis berkeinginan untuk melakukan penelitian probabilitas waktu tunggu di bagian LAA Universitas Bunda Mulia didalam melayani para mahasiswa dan dosen dengan metode simulasi.

Penelitian ini sangat penting untuk dilakukan, untuk mengetahui rata-rata waktu tunggu, probabilitas menunggu, persentase kesibukan, jumlah orang yang menunggu lebih dari waktu tertentu, probabilitas jumlah orang yang menunggu lebih dari waktu tertentu, serta berguna bagi LAA untuk mengetahui rata-rata jeda waktu datangnya para mahasiswa atau dosen yang ingin mendapatkan pelayanan, rata-rata waktu tunggu mahasiswa dan dosen yang ingin mendapatkan pelayanan, rata-rata waktu pelayanan bagi mahasiswa dan dosen yang mendapatkan pelayanan dari LAA, rata-rata waktu yang dihabiskan mahasiswa dan dosen dari saat datang sampai berakhirnya pelayanan LAA, 
dan bagaimana kinerja bagian LAA Universitas Bunda Mulia untuk melayani para mahasiswa dan dosen.

Dengan metode simulasi, tujuan jangka panjang penelitian ini adalah untuk mengetahui apakah perlu dilakukan perubahan efektifitas dan efisiensi di layanan administrasi akademik Universitas Bunda Mulia.

Dipilih metode simulasi karena simulasi merupakan salah satu teknik manajemen operasional yang dapat digunakan untuk menganalisa suatu keadaan dan tingkah laku dari suatu sistem antrian dalam rentang intensitas trafik yang sangat teratur (normal distribution), cukup teratur (uniform distribution), maupun tidak teratur (random distribution) yang mewakili sistem yang nyata (the real-world system).

Tinjauan Pustaka didasarkan pada beberapa literature, seperti operations management, management science, quantitative methods for business, and quantitative analysis for management. Anderson et al. (2008:607), "A simulation model of a waiting line system where the state of the system, including the number of customers in the waiting line and whether the service facility is busy or idle, changes or evolves over time is referred to as dynamic simulation model. Dynamic simulation model could be used to compute the steady-state operating characteristics of a waiting line, including the average waiting time, the average number of units in the waiting line, and the probability of waiting. In most cases, the waiting line formulas were based on specific assumptions about the probability distribution for arrivals, the probability distribution for service times, and the queue discipline. Simulation as an alternative for studying waiting lines, is more flexible. In applications where the assumptions required by the waiting line formulas are not reasonable, simulation may be the only feasible approach to studying the waiting line system".

Menurut Heizer (2009:662), "Simulation is the attempt to duplicate the features, appearance, and characteristics of a real system, usually via a computerized model. The model will then be used to estimate the effects of various actions". The idea behind simulation is threefold:

1. To imitate a real-word situation mathematically.

2. Then to study its properties and operating characteristics. 
3. Finally to draw conclusions and make action decisions based on the results of the simulation.

To use simulation, we should:

1. Define the problem.

2. Introduce the important variables associated with the problem.

3. Construct a numerical model.

4. Set up possible courses of action for testing by specifying values of variables.

5. Run the experiment.

6. Consider the results (possibly modifying the model or changing data inputs).

7. Decide what course of action to take.

Menurut Stevenson, W.J., Ozgur, C. (2007:724-727), "Simulation involves the use of a model that exhibits the important behavioral characteristics of a real system". In each of the examples, an important benefit of simulation is the ability to experiment with a situation under controlled conditions. Thus, simulation is used to answer "What if ...?" questions. In designing a simulation, an analyst is typically guided by this basic principle: Of necessity, the simulation model will be a simplification of reality. However, it must be realistic enough to provide meaningful results so that it will be useful for problemsolving and decision making.

Simulation typically involves these steps:

1. Defining the problem and setting objectives.

2. Gathering data.

3. Developing the model.

4. Validating the model.

5. Designing experiments.

6. Performing simulation runs.

7. Analyzing and interpreting the results.

Contoh-contoh persoalan dan penelitian yang dapat dilakukan dan diselesaikan dengan metode simulasi, diantaranya adalah: automated teller machine queuing-line system, ambulance location and dispatching, assembly-line balancing, parking lot and harbor design, distribution system design, scheduling aircraft, labor-hiring decisions, personnel scheduling, traffic-light timing, voting pattern prediction, bus scheduling, 
design of library operations, taxi, truck, and railroad dispatching, production facility scheduling, plant layout, capital investments, production scheduling, sales forecasting, inventory planning and control.

Penelitian ini menggunakan metode simulasi yang dipelajari di mata kuliah operations management, management science, quantitative methods for business, dan quantitative analysis for management.

Data yang harus dan akan didapatkan untuk penelitian di layanan administrasi akademik Universitas Bunda Mulia, diantaranya adalah:

-Waktu jeda kedatangan (interarrival time) yang paling minimal

-Waktu jeda kedatangan (interarrival time) yang paling maksimal

-Rata-rata waktu pelayanan (service time)

-Standard deviasi waktu pelayanan (service time)

Menurut Anderson et al. (2008:619) dan Render (2009:647), dipilih metode simulasi karena metode simulasi mempunyai beberapa keunggulan sebagai berikut:

-Simulasi dapat digunakan untuk mempelajari dan menganalisa suatu sistem yang kompleks dan sulit di kehidupan yang nyata.

-Secara umum, lebih besar jumlah probability yang ada di dalam suatu sistem, maka akan semakin bagus bagi metode simulasi di dalam melakukan suatu pendekatan secara matematis untuk mempelajari sistem tersebut.

-Model simulasi memberikan kemudahan di dalam melakukan eksperimen untuk suatu sistem yang nyata.

-Perubahan asumsi atau perubahan operasi di metode simulasi dapat dengan mudah dilakukan dan hasilnya akan memberikan prediksi bagaimana perubahan tersebut mempengaruhi operasi suatu sistem di dalam kehidupan yang nyata. -Simulasi memungkinkan untuk mempelajari efek yang saling mempengaruhi antara suatu komponen atau variabel dan dapat digunakan untuk menentukan variabel mana yang paling penting.

-Simulasi dapat digunakan untuk menyelesaikan suatu problem yang kompleks di dalam kehidupan yang nyata, yang umumnya tidak dapat diselesaikan dengan metode kuantitatif analisis yang lainnya. Sebagai contoh, beberapa model antrian 
(queuing model) membutuhkan penyelesaian dengan Poisson Distribution sedangkan beberapa inventory model dan network model membutuhkan normality data atau data yang terdistribusi normal.

-Sebagai tambahan model simulasi akan memberikan alternatif atau peringatan yang lebih baik dari suatu strategi keputusan yang salah di dalam manajemen, dan akan memberikan gambaran atau proyeksi mengenai kesalahan suatu sistem, kerugian dan lain-lain.

-Model simulasi sangatlah unik dan dapat dipergunakan secara baik untuk membuat atau menentukan suatu keputusan yang sangat penting di dalam manajemen operasional.

Menurut Anderson et al. (2008:619) dan Render (2009:647), metode simulasi juga mempunyai beberapa keterbatasan sebagai berikut:

-Simulasi tidak menghasilkan suatu solusi yang optimal terhadap suatu permasalahan bila dibandingkan dengan metode kuantitatif analisis yang lainnya seperti economic order quantity, linear programming atau PERT, akan tetapi selalu menghasilkan solusi yang mendekati optimal.

-Jika simulasi dilakukan dengan baik dan teliti maka hasil simulasi akan menjadi sangat baik.

Menurut Anderson et al. (2008:620), "Using simulation, we can ask what-if questions and project how the real system will behave. Although simulation does not guarantee optimality, it will usually provide near-optimal solutions. In addition, simulation models often warn against poor decision strategies by projecting disastrous outcomes such as system failures, large financial losses, and so on". 


\section{Gambar 1. Flowchart for Waiting Line Simulation}

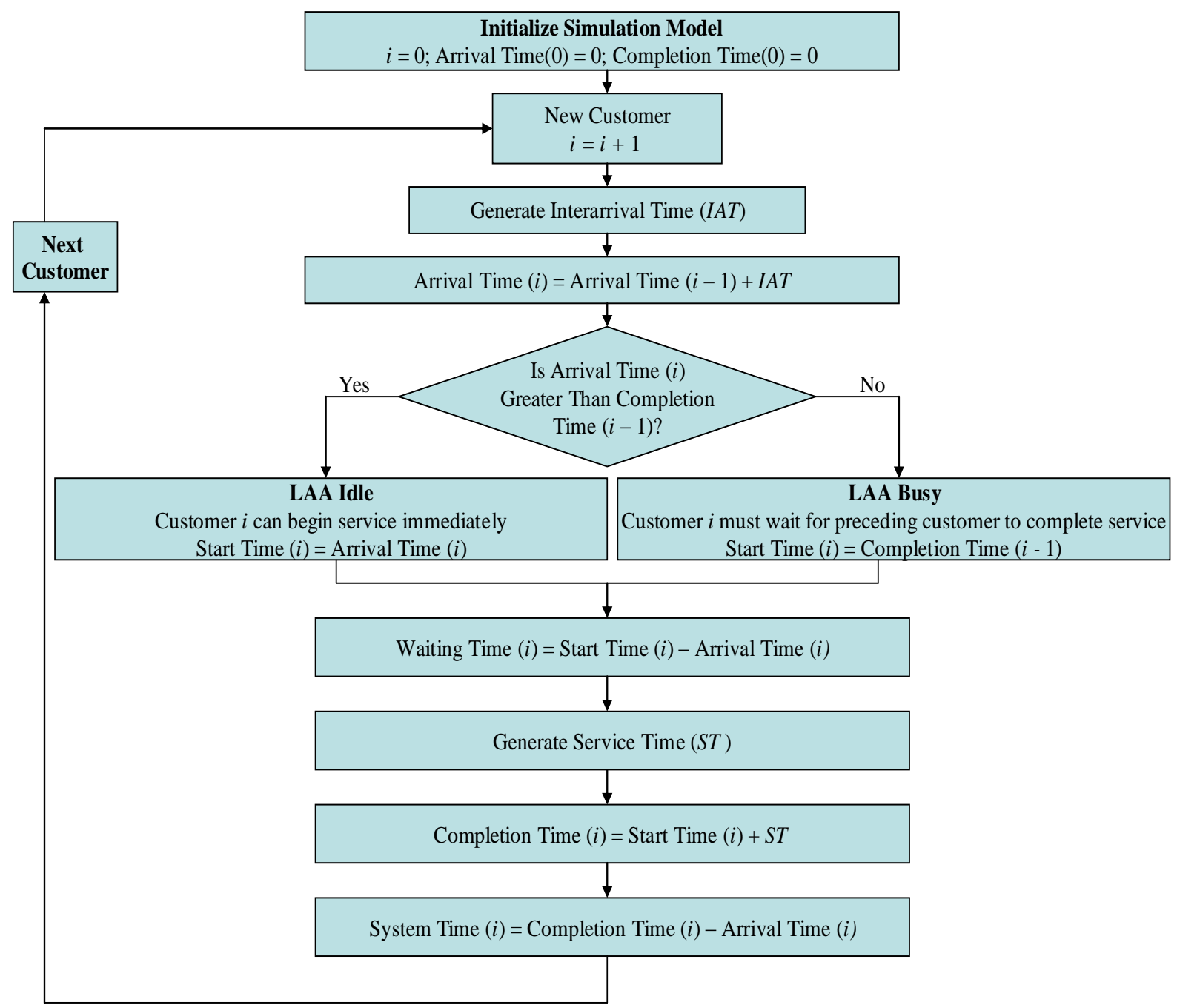




\section{Tabel 1. Simulation Example}

\begin{tabular}{|c|c|c|c|c|c|c|c|}
\hline \multicolumn{8}{|c|}{ Simulation Example } \\
\hline \multirow[t]{2}{*}{ Customer } & Interarrival & \multirow{2}{*}{$\begin{array}{c}\text { Arrival } \\
\text { Time } \\
\end{array}$} & \multirow{2}{*}{$\begin{array}{l}\text { Start } \\
\text { Time } \\
\end{array}$} & \multirow{2}{*}{$\begin{array}{c}\text { Waiting } \\
\text { Time }\end{array}$} & \multirow{2}{*}{$\begin{array}{c}\text { Service } \\
\text { Time } \\
\end{array}$} & \multirow{2}{*}{$\begin{array}{c}\text { Completion } \\
\text { Time } \\
\end{array}$} & \multirow{2}{*}{$\begin{array}{l}\text { Time in } \\
\text { System }\end{array}$} \\
\hline & \multirow[t]{2}{*}{ Time } & & & & & & \\
\hline & & & & & & & \\
\hline 1 & 1.4 & 1.4 & 1.4 & 0.0 & 2.3 & 3.7 & 2.3 \\
\hline 2 & 1.3 & 2.7 & 3.7 & 1.0 & 1.5 & 5.2 & 2.5 \\
\hline 3 & 4.9 & 7.6 & 7.6 & 0.0 & 2.2 & 9.8 & 2.2 \\
\hline 4 & 3.5 & 11.1 & 11.1 & 0.0 & 2.5 & 13.6 & 2.5 \\
\hline 5 & 0.7 & 11.8 & 13.6 & 1.8 & 1.8 & 15.4 & 3.6 \\
\hline 6 & 2.8 & 14.6 & 15.4 & 0.8 & 2.4 & 17.8 & 3.2 \\
\hline 7 & 2.1 & 16.7 & 17.8 & 1.1 & 2.1 & 19.9 & 3.2 \\
\hline 8 & 0.6 & 17.3 & 19.9 & 2.6 & 1.8 & 21.7 & 4.4 \\
\hline 9 & 2.5 & 19.8 & 21.7 & 1.9 & 2.0 & 23.7 & 3.9 \\
\hline 10 & 1.9 & 21.7 & 23.7 & 2.0 & 2.3 & 26.0 & 4.3 \\
\hline Tatals & 2170 & & & 1120 & 2090 & & 3210 \\
\hline & & & & & & & \\
\hline Averages & 2.17 & & & 1.12 & 2.09 & & 3.21 \\
\hline & & & & & & & \\
\hline & & & & & & & \\
\hline Customer 1: & & & & & & & \\
\hline Interarrival tim & $(\mid \mathrm{AT})=1.4 \mathrm{me}$ & akan diha & dengan & & & & \\
\hline Karena simula & i mulai dari 0 , & ka arrival & Istomer & $+1.4=1.4$ & & & \\
\hline Customer $1 \mathrm{at}$ & an segera men & gatkan pel & , denga & time $=1.4$ & & & \\
\hline Waiting time f & r cutomer $1=$ & it time - at & $n e=1.4$ & $=0$ menit & & & \\
\hline Service time ( & T) $=2.3$ menit & an dihasilk & Igan sim & & & & \\
\hline Completion tir & e for customer & $=$ start tim & vice tim & $+2.3=3$ & enit & & \\
\hline Time in the sy & tem for custom & $1=\mathrm{comp}$ & ime - ar & $\mathrm{e}=3.7-$ & 2.3 menit & & \\
\hline & & & & & & & \\
\hline Customer 2: & & & & & & & \\
\hline Interarrival tim & $(\mid \mathrm{AT})=1.3 \mathrm{me}$ & akan diha & dengan & & & & \\
\hline Karena arrival & me customer & 1.4, mak & time $\mathrm{cl}$ & $r 2=1.4+$ & $=2.7$ menit & & \\
\hline Karena custor & er 1 baru seles & dalam wal & menit, o & ena arrival & customer 2 & $=2.7$ menit $<3$ & menit \\
\hline Maka custom & 2 akan mend & tkan pela & ada 3.7 & yang mer & tan start time & untuk custom & \\
\hline Waiting time & $r$ customer $2=$ & art time - & $m e=3$. & $=1$ menit & & & \\
\hline Service time ( & T) $=1.5$ menit & an dihasill & gan sim & & & & \\
\hline Completion tir & e for customer & $=$ start tim & vice tim & $+1.5=5$ & enit & & \\
\hline Time in the sy & tem for custom & $2=\operatorname{comp}$ & ime - arr & $\mathrm{he}=5.2-2$ & 2.5 menit & & \\
\hline & & & & & & & \\
\hline Customer 3: & & & & & & & \\
\hline Interarrival tim & $(\mathrm{ATT})=4.9 \mathrm{me}$ & akan diha & dengan & & & & \\
\hline Karena arrival & me customer 2 & 2.7, mak & time $\mathrm{Cl}$ & $r 3=2.7+$ & $=7.6$ menit & & \\
\hline Karena custor & er 2 sudah sel & i dalam $w$ & 2 menit & arena arriv & ne customer & $=7.6$ menit $>$ & 2 menit \\
\hline Maka custom & 3 akan seger & iendapatk & yanan, & start time & 6 menit & & \\
\hline Waiting time f & r customer $3=$ & art time - & $m e=7$ & $=0$ menit & & & \\
\hline Service time ( & T) $=2.2$ menit & an dihasilk & gan sim & & & & \\
\hline Completion tir & e for customer & $=$ start tim & vice tim & $+2.2=9$ & enit & & \\
\hline Time in the sy & tem for custom & $3=\operatorname{comp}$ & ime - arr & $\mathrm{he}=9.8-7$ & 2.2 menit & & \\
\hline
\end{tabular}




\section{Hasil Penelitian dengan Metode Simulasi:}

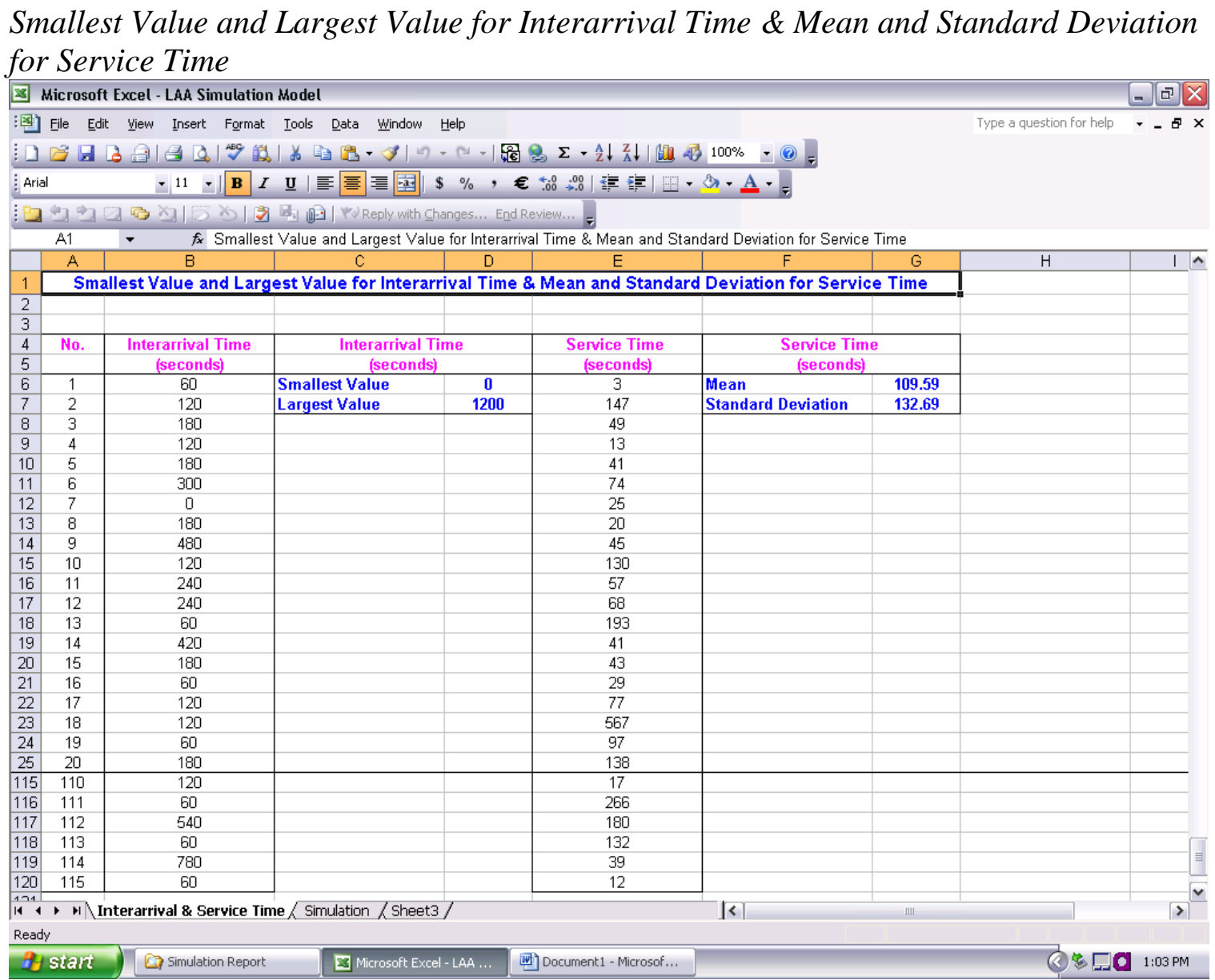




\section{Hasil Penelitian dengan Metode Simulasi (continued):}

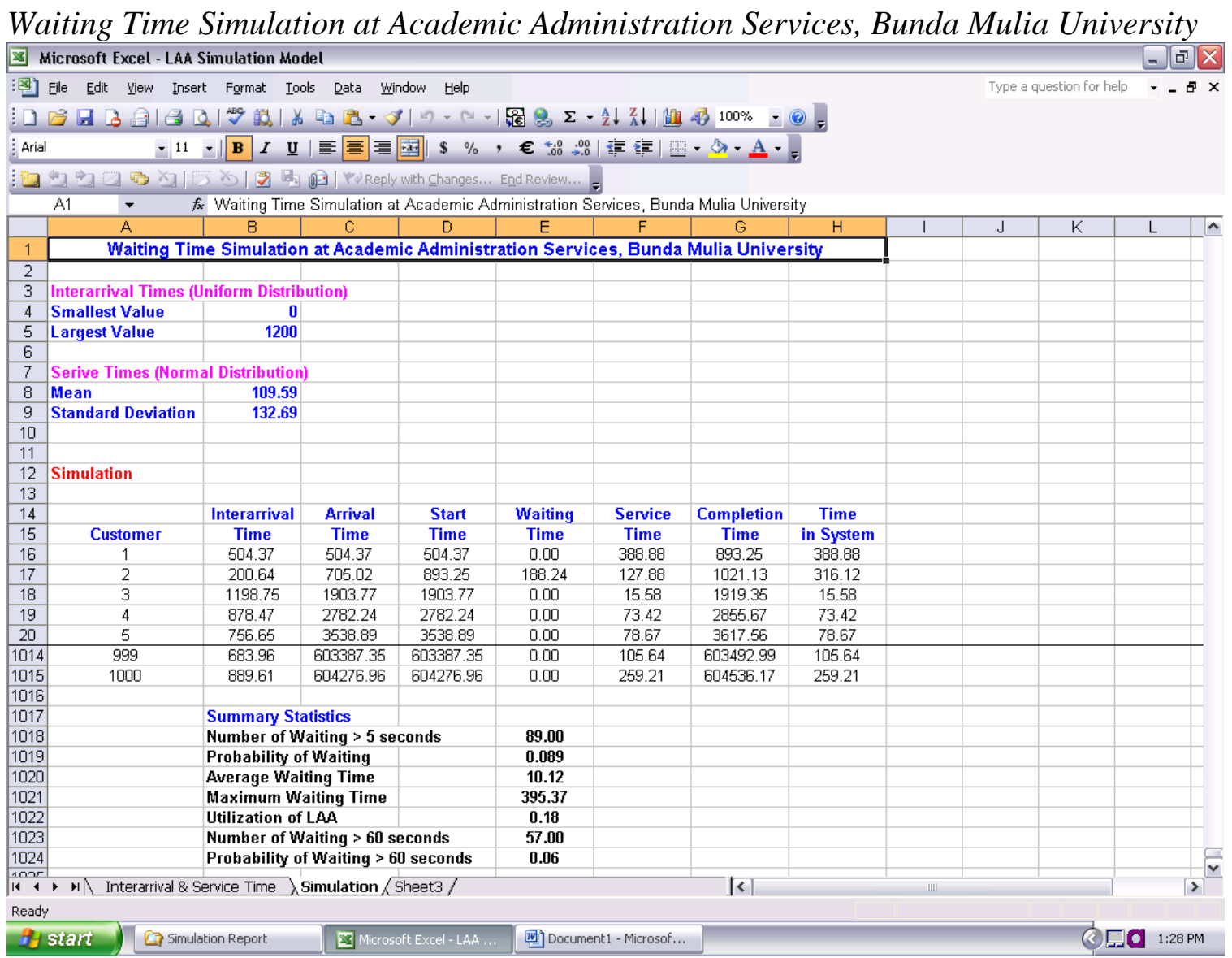




\section{Kesimpulan dan Saran:}

Dari 1000 data simulasi yang diciptakan (generated or created simulation) atau 1000 kali kemungkinan pelayanan di bagian layanan administrasi akademik Universitas Bunda Mulia, maka dapat diambil kesimpulan sebagai berikut:

-Jumlah yang menunggu $>5$ detik dalam simulasi ini adalah 89 orang

-Probabilitas waktu menunggu adalah kecil yaitu $8.9 \%$

-Rata-rata waktu menunggu adalah rendah yaitu 10.12 detik

-Waktu menunggu maksimal juga relatif kecil yaitu 395.37 detik

-Kinerja dan utilization of LAA juga belum maksimal yaitu rata-rata $18 \%$

-Jumlah yang menunggu $>60$ detik kemungkinan ada 57 orang

-Probabilitas menunggu > 60 detik juga kecil yaitu $6 \%$

Di sini jelas terlihat bahwa baik mahasiswa maupun dosen Universitas Bunda Mulia masih dapat terlayani dengan baik, karena kecilnya jumlah yang menunggu $>5$ detik dalam simulasi 1000 kali, yaitu cuma terjadi 89 kali, dan probabilitas waktu menunggu tersebut juga kecil yaitu cuma $8.9 \%$, sedangkan rata-rata waktu menunggu adalah sangat kecil yaitu cuma 10.12 detik, sedangkan waktu menunggu maksimal juga relatif kecil yaitu 395.37 detik. Sedangkan jumlah yang menunggu > 60 detik kemungkinannya ada 57 orang dan probabilitas waktu menunggu > 60 detik juga kecil kemungkinannya yaitu cuma $6 \%$.

Dapat disimpulkan bahwa tidaklah perlu dilakukan perubahan efektivitas dan efisiensi di layanan administrasi akademik Universitas Bunda Mulia.

Sedangkan kinerja di bagian layanan administrasi akademik secara keseluruhan (overall) dapat dianggap sangat baik dan sangat idle karena utilization of LAA juga belum maksimal yaitu sebesar rata-rata 18\%, atau dapat dianggap bahwa beban kerja di bagian LAA tidaklah terlalu berlebihan dan dianggap masih dapat dengan baik dan layak melayani para mahasiswa dan dosen Universitas Bunda Mulia, sehingga dapat disimpulkan bahwa kinerja bagian layanan administrasi akademik Universitas Bunda Mulia dapat dianggap sangat baik ditinjau dari sisi manajemen operasional, karena beban pekerjaan tidaklah terlalu berlebihan, akan tetapi secara keseluruhan (overall) dapat dianggap bahwa tidaklah terjadi suatu pelayanan yang dianggap tidak memuaskan baik kepada mahasiswa maupun kepada dosen Universitas Bunda Mulia, karena bagian 
pelayanan dapat dengan sigap melayani dengan segera yang ditunjukkan dengan rata-rata waktu menunggu adalah sangat kecil yaitu cuma 10.12 detik.

Saran yang perlu penulis berikan di sini adalah jika dipandang dari sisi manajemen operasional, maka yang paling efektif adalah tempat pelayanan haruslah berbentuk oval dan bulat atau setengah lingkaran agar dapat melayani para mahasiswa dan dosen secara lebih ergonomics, efektif dan efisien.

Saran lainnya adalah agar para petugas pelayanan di bagian layanan administrasi akademik Universitas Bunda Mulia tidaklah duduk di satu tempat yang berdekatan atau mengumpul menjadi satu akan tetapi haruslah duduk secara berderet membentuk oval atau setengah lingkaran agar dapat melayani para mahasiswa dan dosen secara lebih ergonomics, efektif dan efisien.

Analisis dan saran untuk suatu saat tertentu dimana pelayanan LAA dalam kondisi yang sedang ramai, misalnya saat ujian, disarankan:

- Untuk menambah 1 atau 2 orang karyawan di bagian LAA, misalnya dengan penugasan khusus atau overtime. Tetapi sebelum menambah karyawan yang bertugas di bagian LAA, perlu dilihat dahulu apakah perhitungan simulation utilization untuk LAA sudah sangat sibuk, misalnya sudah mendekati 70\%?

- Disain tempat bagian pelayanan LAA sebaiknya di ubah menjadi bentuk U ( $U$ shape), sesuai dengan prinsip manajemen operasional dimana bentuk $\mathrm{U}$ akan lebih efektif dan efisien di dalam menangani pelayanan.

- Gambar bentuk U dalam manajemen operasional adalah sebagai berikut:

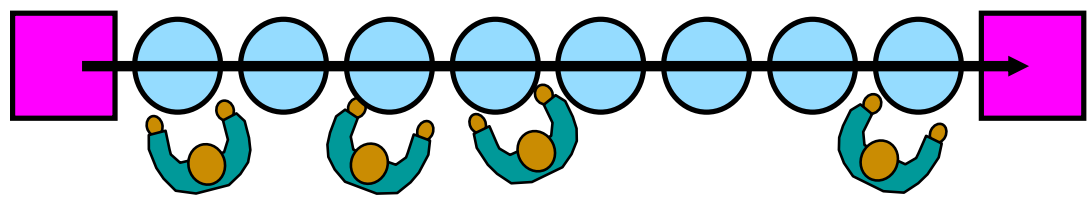

Current layout - straight lines make it hard to balance tasks because work may not be divided evenly 


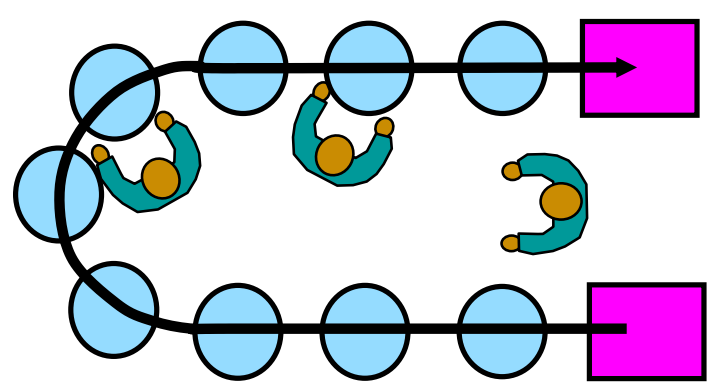

Improved layout - in U shape, workers have better access. Four cross-trained workers were reduced

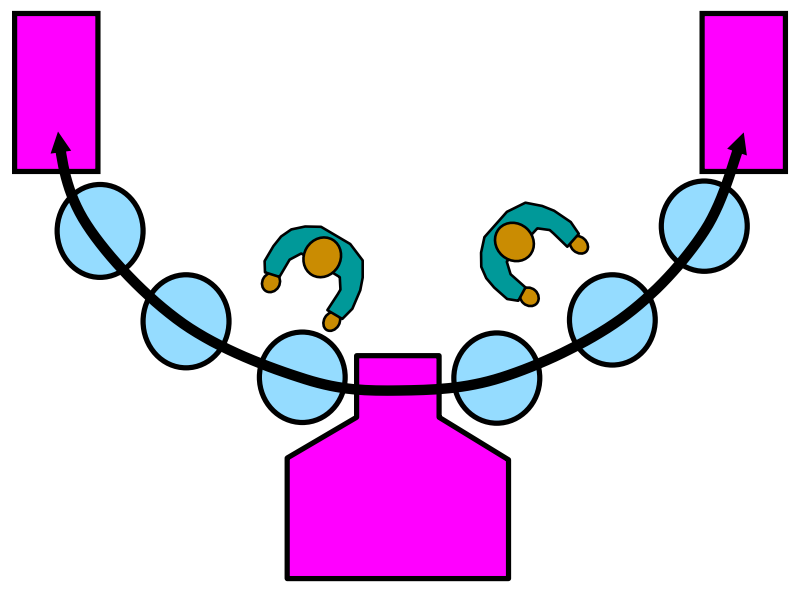

Improved layout - cross-trained workers can assist each other. May be able to add a third worker as additional output is needed

(Heizer \& Render, Operations Management, $9^{\text {th }}$ edition, 2008, page 362)

$U$-shaped line may reduce employee movement and space requirements while enhancing communication, reducing the number of workers, and facilitating inspection

Atau dengan kata lain, bahwa bentuk disain $U$ akan mengurangi pergerakan karyawan dan tempat pelayanan yang dibutuhkan serta dapat meningkatkan komunikasi pelayanan, dapat pula mengurangi jumlah karyawan di bagian pelayanan, dan dapat memfasilitasi pemeriksaan kebutuhan akan pelayanan dengan lebih baik. Jadi dapat dikatakan fasilitas pelayanan akan menjadi lebih produktif, efektif dan lebih efisien. 


\section{Daftar Pustaka:}

Anderson, D.R., et al., 2008. An Introduction to Management Science, Quantitative

Approaches to Decision Making (12 ${ }^{\text {th }}$ ed.). South-Western, a division of Thomson

Learning.

Anderson, D.R., et al, 2008. Quantitative Methods for Business ( $11^{\text {th }}$ ed.). South-Western, a division of Thomson Learning.

Balakrishnan, N., Render, B., Stair, R.M., 2007. Managerial Decision Modeling with Spreadsheets ( $2^{\text {nd }}$ ed.). Pearson Education, Inc., Upper Saddle River, New Jersey.

Heizer, J., Render, B., 2008. Operations Management ( $9^{\text {th }}$ ed.). Pearson Education, Inc., Upper Saddle River, New Jersey.

Heizer, J., Render, B., 2009. Flexible Edition Operations Management $\left(9^{\text {th }}\right.$ ed.). Pearson Education, Inc., Upper Saddle River, New Jersey.

Hillier, F.S. et al., 2008. Introduction to Management Science ( $3^{\text {rd }}$ ed.). McGrawHill/Irwin, New York.

Law, Averill., 2007. Simulation Modeling and Analysis with Expertfit Software $\left(4^{\text {th }}\right.$ ed.). McGraw-Hill/Irwin, New York.

Render, B., Stair, R.M., Hanna, M.E., 2009. Quantitative Analysis for Management (10 ${ }^{\text {th }}$ ed.). Pearson Education, Inc., Upper Saddle River, New Jersey.

Stevenson, W.J., 2009. Operations Management (10 ${ }^{\text {th }}$ ed.). McGraw-Hill/Irwin, New York.

Stevenson, W.J., Ozgur, C., 2007. Introduction to Management Science with Spreadsheets. McGraw-Hill/Irwin, New York.

Taha, H.A., 2007. Operations Research: An Introduction $\left(8^{\text {th }}\right.$ ed.). Pearson Education, Inc., Upper Saddle River, New Jersey.

Taylor, B.W., 2007. Introduction to Management Science $\left(9^{\text {th }}\right.$ ed.). Pearson Education, Inc., Upper Saddle River, New Jersey.

Waters, Donald., 2008. Quantitative Methods for Business (4 ${ }^{\text {th }}$ ed.). Pearson Education, Inc., Upper Saddle River, New Jersey.

Winston, W.L., Albright, S.C., 2007. Practical Management Science ( $3^{\text {rd }}$ ed.). SouthWestern, a division of Thomson Learning. 
Analisa Waktu Tunggu Di Layanan Administrasi Akademik Universitas Bunda Mulia Dengan Metode Simulasi

Wisniewski, Mik., 2009. Quantitative Methods for Decision Makers (5 ${ }^{\text {th }}$ ed.). Pearson

Education, Inc., Upper Saddle River, New Jersey. 